\title{
Response To Pretransplant Downstaging Therapy Predicts Patient Outcome After Liver Transplantation For Hepatocellular Carcinoma With Portal Vein Tumor Thrombus
}

\section{Zhe Yang}

Zhejiang Shuren University

\section{Shuo Wang}

Zhejiang Shuren University

Jingqi Sun

Zhejiang University

\section{Li Zhuang}

Zhejiang Shuren University

\section{Qiyong Li}

Zhejiang Shuren University

\section{Xiao Xu}

Zhejiang University

Shusen Zheng ( $\nabla$ zyzss@zju.edu.cn )

\section{Research}

Keywords: Response to downstaging, Hepatocellular carcinoma, Liver transplantation, Portal vein tumor thrombus, Outcome

Posted Date: July 20th, 2020

DOI: https://doi.org/10.21203/rs.3.rs-41646/v1

License: (c) (1) This work is licensed under a Creative Commons Attribution 4.0 International License. Read Full License

Version of Record: A version of this preprint was published at Hepatobiliary \& Pancreatic Diseases International on October 1st, 2021. See the published version at https://doi.org/10.1016/j.hbpd.2021.09.012. 


\section{Abstract}

Background: Tumor viability and areas of necrosis after pretransplant downstaging therapy is predictive of patient outcome, but has not been evaluated in hepatocellular carcinoma (HCC) recipients with portal vein tumor thrombus (PVTT).

Methods: Recurrence-free survival (RFS) and overall survival (OS) were compared among PVTT-HCC patients receiving pretransplant downstaging therapy with and without well response (radiographic tumor necrosis $>50 \%$ ). Multivariable predictors of well response to downstaging were identified.

Results: Of 107 patients, downstaging was attempted in 48, and 15 had well response to pretransplant therapy. Compared with poor response and non-downstaged patients, well response patients had significantly superior $1-, 2$-, and 3 -year RFS $(72 \%, 72 \%$, and $72 \%$ vs $30.4 \%, 22.6 \%$, and $22.6 \%$; $P=0.002)$ and OS $(100 \%, 90.9 \%$, and $90.9 \%$ vs $66.3 \%, 47.7 \%$, and $47.7 \% ; P=0.008)$. Pre-transplant alpha-fetoprotein (AFP) level $<1000 \mathrm{ng} / \mathrm{mL}$ and radiographic tumor necrosis $>50 \%$ were independent favorable factors for lower HCC recurrence rate and better overall survival after liver transplantation (LT). Multivariable predictors of well response to downstage included well-moderate differentiated tumor on explant and multiple combined pretransplant locoregional and systematic therapies.

Conclusions: For HCC patients with PVTT and receive pretransplant downstaging therapy, achieving well response is predictive of significantly better posttransplant outcomes and patients can have acceptable survival with LT after successful downstaging. Combined locoregional and systematic therapies may help to improve the responsiveness to downstaging.

\section{Background}

Liver transplantation (LT) is the optimal treatment for selected patients with severe liver cirrhosis and unresectable hepatocellular carcinoma (HCC), who are fulfilling with Milan criteria 1 1》. However, Milan criteria is too restrictive and many centers have expanded the selection criteria by incorporating surrogates of tumor biology such as alpha fetoprotein (AFP), vitamin K absence/antagonist-II (PIVKA-II), neutrophil to lymphocyte ratio (NLR) and tumor standard uptake value (SUV) defined by positron

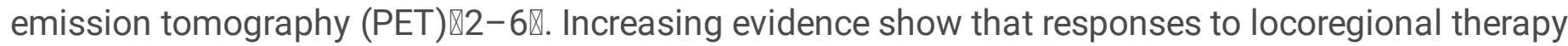
(LRT) can accurately reflect tumor biology and complete pathologic response to LRT is associated with

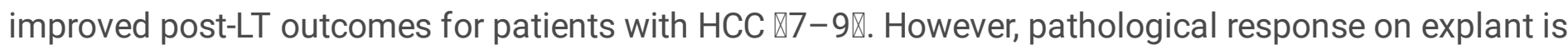
unable to be detected after pre-LT LRT. Identification of knowable preoperative radiographic factors that can risk stratify HCC patients thus is an area of much demand.

The role of LT for the treatment of HCC patients with PVTT is controversial. Increasing studies have shown that a subset of the PVTT-HCC patients with favorable tumor biology could have acceptable postLT outcome, especially for those after successful preoperative downstaging $₫ 4,10-12 \rrbracket$. Preoperative neoadjuvant therapies to improve prognosis of HCC patients with PVTT have been suggested in recent studies $₫ 11,12 \rrbracket$. A Japanese study showed that curative surgical resection after down-staging by three- 
dimensional conformal radiation therapy for PVTT combined with hepatic arterial infusion chemotherapy for advanced HCC results in good long-term survival $₫ 13 \bigotimes$.

We aim to analyze the rate of well radiographic response to pretransplant downstaging therapy in PVTTHCC patients, evaluate the impact of well response on post-LT HCC recurrence and survival, and identify factors that predict the ability to achieve well response. These predictors may aid to define a tumor's biology and maximize the benefit of LT for HCC patients with PVTT.

\section{Methods}

107 hepatocellular carcinoma (HCC) patients with PVTT transplanted during the period of April 2016 to October 2019 were enrolled. Patients with extrahepatic metastasis or with invasion of hepatic vein and inferior vena cava were excluded. HCC diagnosis was confirmed by posttransplant pathology. The diagnosis of PVTT were based on pre-transplant radiological characteristics (including enhanced CT scan and MRI) and pathology of the specimen. PVTT was classified as follows $₫ 14 \rrbracket$ : (1) Vp1: tumor thrombus distal to the second branch of the portal vein; (2) Vp2: tumor thrombus in the second branch of the portal vein; (3) Vp3: tumor thrombus in the first branch of portal vein; (4) Vp4: main portal trunk tumor thrombus. All patients received modified piggyback LT, "no touch" hepatectomy technique was adopted to minimize tumor cell seeding. Complete clinical and laboratory data were available before operation and during follow-up. The present study was conducted with the approval of the Institutional Review Board and Ethics Committee of the Shulan Hospital, Zhejiang Shuren University School of Medicine (Hangzhou, China) and in accordance with the Declaration of Helsinki. Thus, the study conformed to international and national regulations. Informed consent was obtained from all of the patients.

Treatment modalities for HCC downstaging consisted of loco-regional and systematic therapy.

Transarterial chemoembolization (TACE) and radiofrequency ablation were the predominant loco-regional treatment modalities. Systematic therapies include multikinase inhibitors (sorafenib or lenvatinib) and programmed cell death protein 1 (PD-1) antibody. Patient variables included age, sex, pretransplant AFP, NLR, platelet to lymphocyte ratio (PLR), C-reaction protein (CRP), maximum tumor diameter, total tumor diameter, total tumor number, tumor differentiation, degree of PVTT and response to pretransplant downstaging therapy. Patients were categorized into 3 groups: with well radiographic response, poor radiographic response and non-downstaged patients. Well radiographic response was defined as more than $50 \%$ necrosis or nonviable tumor according to abdominal CT or MRI scan, and poor radiographic response patients were with less than $50 \%$ necrosis or nonviable tumor on radiology. The median interval time from downstaging therapy to LT was 3.0 months (1.1-10.4 months).

Recipients were followed up closely from the date of operation to death or the last follow-up. Recurrence was identified by elevation of tumor biomarkers (AFP or PIVKA-II) and positive imaging findings. The median follow up time was 16.4 months (1.5-47.5 months). Post-transplant immunosuppression (IS) protocol was tacrolimus based (6-10 ng/ml within 3 months, 6-12 months $3-5 \mathrm{ng} / \mathrm{ml}$, beyond 12 months less than $3 \mathrm{ng} / \mathrm{ml}$ ) and glucocorticoid was given $1000 \mathrm{mg}$ intraoperatively with steroid-free 
regimen post-transplantation. Basiliximab was administrated $20 \mathrm{mg}$ at the first and the fourth day following LT.

OS was defined as the time from transplantation to death or last follow-up. RFS was defined as a period from transplantation to recurrence or last follow-up without recurrence. Continuous variables were described as median and interquartile range, and categorical variables were described as frequency and percentage. OS and RFS rates were analyzed by the Kaplan-Meier method and log-rank test. Independent prognostic indicators were assessed by using Cox's proportional hazard model. A logistic regression model was used to assess the candidate predictors on the odds of achieving well radiographic response. Values of $P<0.05$ was considered statistically significant.

\section{Results}

\section{Baseline Demographics of patients}

Among the 107 HCC patients with PVTT, 48 patients received pretransplant downstaging therapy for HCC with $15(31 \%)$ patients had well response on radiology. Patient, tumor and pretransplant treatment characteristics are shown in Table 1. To summarize, the median age was 49 years [interquartile range (IQR) 42-56], and $97 \%$ were male. Hepatitis B virus (HBV) infection was the underlying liver disease. The median pre-transplant AFP was 602.6 (IQR 30.8-13719) ng/ml. The pre-transplant systematic inflammatory index such as NLR, PLR and CRP were 4.9 (IQR 3.4-8.5), 153 (IQR 94-234) and 18 (IQR 6.1$38.8) \mathrm{mg} / \mathrm{L}$, respectively. The majority of patients (89.6\%) received TACE, with $66.7 \%$ receiving TACE alone and $22.9 \%$ receiving TACE and systematic therapies (sorafenib, lenvatinib or PD-1 antibody). Only $10.4 \%$ of patients received other treatments (thermal ablation, radiotherapy, lenvatinib or PD-1 antibody) without TACE. Concerning the pathology of extracted liver, 47 (43.9\%) patients had poorly differentiated HCC, 88 (82.2\%) patients had multifocal tumor, 45 (42.1\%) patients had Vp4-PVTT and 80 (74.8\%) patients had total tumor size larger than $8 \mathrm{~cm}$.

\section{Univariate and Multivariate Analysis of Predictors of Well Response to Downstaging Therapy}

Among the $48 \mathrm{HCC}$ patients received pretransplant downstaging therapy, 15 (31\%) patients had well response on radiology and $33(69 \%)$ patients had poor response to pretransplant downstaging therapy. Univariate predictors of well response to downstaging are shown in Table 2. In summary, patients were less likely to achieve well response to downstaging with pre-transplant AFP $\geq 1000 \mathrm{ng} / \mathrm{mL}$ (OR $0.184,95 \%$ $\mathrm{Cl}, 0.044-0.778, \mathrm{P}=0.021)$, pre-transplant $\mathrm{PLR} \geq 120$ (OR 0.208, 95\% $\mathrm{Cl}, 0.054-0.799, \mathrm{P}=0.022)$, total tumor size larger than $8 \mathrm{~cm}(\mathrm{OR} 0.254,95 \% \mathrm{Cl}, 0.066-0.976, \mathrm{P}=0.046)$; or poorly differentiated HCC (OR 0.110 , $95 \% \mathrm{Cl}, 0.013-0.939, \mathrm{P}=0.044$ ). Patients who received multiple combined downstaging therapies (TACE, thermal ablation, tyrosine kinase inhibitors or PD-1 antibody) were more likely to achieve well response (OR 6.400, 95\% Cl, 1.593-25.717, P=0.009).

Multivariate modeling identified independent factors associated with well response, as shown in Table 2. poorly differentiated HCC (OR 0.06, $95 \% \mathrm{Cl}, 0.005-0.693, \mathrm{P}=0.024)$ was independent risk factor associated 
with well response, and multiple combined downstaging therapies (OR 10.884, 95\% Cl, 1.909-62.047, $\mathrm{P}=0.007)$ was independent favorable factor associated with well response.

\section{Posttransplant HCC Recurrence and Overall Survival}

Survival outcomes are shown in Figure 1. Compared with poor response or non-downstaged patients, patients who achieved well response to downstage had significantly superior 1-, 2-, and 3-year recurrencefree survival $(72 \%, 72 \%$, and $72 \%$ vs $30.4 \%, 22.6 \%$, and $22.6 \% ; P=0.002 ;$ Fig. $1 \mathrm{~A})$ and overall survival $(100 \%, 90.9 \%$, and $90.9 \%$ vs $66.3 \%, 47.7 \%$, and $47.7 \%$; $=0.008$; Fig. $1 B)$.

As shown in table 3 , by the univariate analysis, pre-transplant AFP $\geq 1000 \mathrm{ng} / \mathrm{mL}, \mathrm{NLR} \geq 7, \mathrm{PLR} \geq 120$, $\mathrm{CRP} \geq 10 \mathrm{mg} / \mathrm{L}$, maximum or total tumor size $>8 \mathrm{~cm}$, poorly differentiated tumor and Vp4-PVTT were risk factors for both HCC recurrence and inferior overall survival. In addition, tumor necrosis $>50 \%$ after downstaging and multiple combined downstaging therapies were both favorable factors for superior recurrence-free survival and overall survival.

In the multivariate analysis, pre-transplant AFP $\geq 1000 \mathrm{ng} / \mathrm{mL}$ was independent risk factors for post-LT HCC recurrence (HR 3.032, 95\% Cl, 1.303-7.057, $\mathrm{P}=0.010$ ) and overall survival (HR 3.287, 95\% Cl, 1.1549.368, $\mathrm{P}=0.026$ ). In addition, tumor necrosis $>50 \%$ after downstaging was associated with superior recurrence-free survival $(\mathrm{HR} 0.311,95 \% \mathrm{Cl}, 0.102-0.954, \mathrm{P}=0.041)$ and overall survival $(\mathrm{HR} 0.116,95 \% \mathrm{Cl}$, 0.015-0.889, $\mathrm{P}=0.038$ ) (Table 4).

\section{Discussion}

PVTT is conventionally considered as a contraindication for LT due to the high risk of posttransplant recurrence and dismal outcome in the context of organ shortage $\$ 15,16 \bigotimes$. However, they still can have some long-term survivors following LT with far superior outcome compared to other alternative therapy. The extent of PVTT affects tumor recurrence and overall survival after LT. Compared with lobar PVTT, segmental PVTT portends significantly lower posttransplant recurrence rate and superior overall survival, especially when the pretransplant AFP is $<100 \mathrm{ng} / \mathrm{mL}$ \17区. A multi-center study from South Korea suggested that if the PVTT was not in the main portal vein and the AFP and PIVKA-II score was less than 300 , LDLT could be performed with an improved prognosis and considered as a curative treatment option \4囚. Our previous study showed pre-transplant AFP level less than $1000 \mathrm{ng} / \mathrm{ml}$ and intrahepatic tumor SUV $_{\max }$ less than 5 were associated with better patient outcomes after LT for PVTT-HCC, and patients with segmental or lobar PVTT and biologically favorable tumors defined by AFP and ${ }^{18} \mathrm{~F}$-FDG SUV $\mathrm{Fax}_{\text {max }}$ might take benefit from LT $₫ 18 \otimes$.

Pretransplant neoadjuvant therapy for advanced HCC patients is recommended to improve patient outcome in recent studies. In South Korea, for HCC patients with macrovascular invasion and achieved successful downstaging, LDLT after combined TACE and 3-dimensional conformal radiotherapy showed

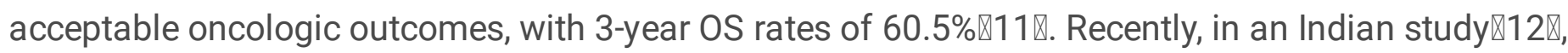
protocol downstaging of HCC with PVTT consisted of stereotactic body radiotherapy (SBRT) for major 
PVTT and chemoembolization or radioembolization for advanced HCC. This group of patients can have acceptable survival after successful downstaging following LDLT. Initial AFP $<400 \mathrm{ng} / \mathrm{ml}$ and AFP fall $>$ $2000 \mathrm{ng} / \mathrm{ml}$ favorably influence survival in these patients.

Increasing evidence suggested that responses to neoadjuvant LRT were important determinants of postLT outcomes for patients with HCC. Besides the serological biomarkers, pathological changes on explant was one of the most important surrogates to evaluate the efficacy of LRT. According to a multicenter study from the United States, for LT recipients with HCC receiving pretransplant LRT, achieving complete pathologic response portends significantly lower posttransplant recurrence and superior survival $\nabla 7 \mathrm{\text { }}$. However, pathological response on explant was unable to be detected after pre-LT LRT. In the present study, preoperative assessment on radiology was introduced, and well radiographic response was defined as more than $50 \%$ necrosis or nonviable tumor according to abdominal CT or MRI scan. Compared with poor response or non-downstaged patients, patients who achieved well response to downstage had significantly superior 1-, 2-, and 3-year recurrence-free survival and overall survival. Tumor necrosis $>50 \%$ after downstaging was independent factor to predict better RFS and OS. According to the literature, complete pathological response after pretransplant therapy ranges from 10 to $54 \%$ in different protocols Q98. In our patients, we saw $31 \%$ HBV background HCC patients with PVTT could achieve well response to pretransplant therapy (with radiographic tumor necrosis $>50 \%$ ).

The treatment modalities for HCC with PVTT include multikinase inhibitors, chemoembolization, radioembolization, immunotherapy and radiology. Previous studies have demonstrated that TACE is

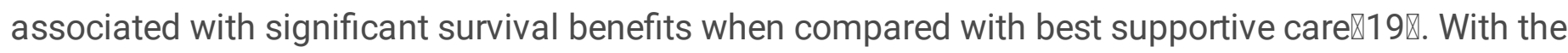
introduction of multikinase inhibitors for HCC, TACE combined with sorafenib could significantly improve

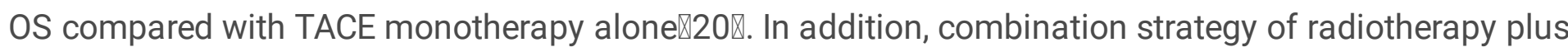

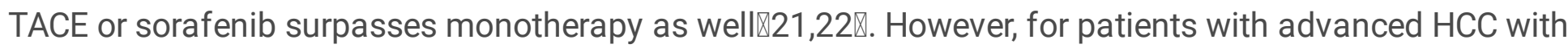
PVTT, there is no significantly difference treated with TACE plus radiotherapy and TACE plus sorafenib in terms of progression-free survival and OS $23 \otimes$. Since the emerging of immunotherapy for HCC, most recent studies on the combination of immune checkpoint inhibitor and anti-angiogenic agent has shown synergic anti-tumor benefits $₫ 24 \rrbracket$. In our study, the majority of patients (89.6\%) received TACE, with $22.9 \%$ receiving TACE and systematic therapies (sorafenib, lenvatinib or PD-1 antibody). Patients who received multiple combined downstaging therapies (TACE, thermal ablation, tyrosine kinase inhibitors or PD-1 antibody) were more likely to achieve well response and better outcomes.

Our study does have some limitations. First of all, our study does not incorporate serological biomarkers, such as AFP slope, to assess the effects of downstaging therapy. We are in the process of evaluating these data as an important next step for study. Second, the combination strategy of pretransplant downstaging modalities for an individual tumor is yet to be optimized. Third, this is a retrospective study and especially confined to a small patient cohort with a short follow-up, and further large-scale analyses are required in order to make saver conclusions.

\section{Conclusion}


For HCC patients with PVTT and receive pretransplant downstaging therapy, achieving well response is predictive of significantly better posttransplant outcomes and patients can have acceptable survival with LT after successful downstaging. Combined locoregional and systematic therapies may help to improve the responsiveness to downstaging.

\section{Abbreviations}

HCC, hepatocellular carcinoma; PVTT, portal vein tumor thrombus; HBV, Hepatitis B virus; AFP, alphafetoprotein; PIVKA-II, vitamin K absence/antagonist-II; NLR, neutrophil to lymphocyte ratio; PLR, platelet to lymphocyte ratio; CRP, C-reaction protein; SUV, standard uptake value; PET, positron emission tomography; LRT, locoregional therapy; TACE, transarterial chemoembolization; RFS, recurrence-free survival; OS, overall survival; $\mathrm{OR}$, odds ratio; $\mathrm{HR}$, hazard ratio; $\mathrm{Cl}$, confidence interval; IQR, interquartile range.

\section{Declarations}

\section{Ethics approval and consent to participate}

Informed consent was obtained from the participants. This study was approved by the Ethical Committee of Shulan Hospital.

\section{Patient consent for publication}

Not applicable.

\section{Availability of data and materials}

The datasets used and/or analyzed during the current study are available from the corresponding author on reasonable request.

\section{Competing interests}

The authors declare that they have no competing interests.

\section{Funding}

This study was supported by the National S\&T Major Project (2017ZX10203205), the Medical Science and Technology Project of Zhejiang Province (2014KYA082) and the Shulan Talent Foundation.

\section{Authors' contributions}

ZY proposed the study. ZY and SW performed the research and wrote the first draft. SW, LZ, QYL and JQS collected and analyzed the data. XX revised the manuscript, valuable comments made throughout the entire process of writing this article, data analysis and editing. SSZ is the guarantor. All authors 
contributed to the design and interpretation of the study and to further drafts. All authors read and approved the final manuscript.

\section{Acknowledgements}

We express our gratitude to all surgeons and nurses for their help in collecting patient information. The authors also would like to thank Bulat Abdrakhimov for correcting this paper.

\section{Author details:}

${ }^{1}$ Department of Hepatobiliary and Pancreatic Surgery, Department of Liver Transplantation, Shulan (Hangzhou) Hospital, Zhejiang Shuren University School of Medicine, Hangzhou 310022, P.R. China. ${ }^{2}$ Division of Hepatobiliary Pancreatic Surgery, First Affiliated Hospital, Zhejiang University School of Medicine, Hangzhou 310003, P.R. China. ${ }^{3}$ National Clinical Research Center of Infectious Diseases, Hangzhou 310003 , P.R. China.

\section{References}

1. Mazzaferro V, Regalia E, Doci R, Andreola S, Pulvirenti A, Bozzetti F, et al. Liver transplantation for the treatment of small hepatocellular carcinomas in patients with cirrhosis. $\mathrm{N}$ Engl $\mathrm{J}$ Med. 1996;334:693-9.

2. Xu X, Lu D, Ling Q, Wei X, Wu J, Zhou L, et al. Liver transplantation for hepatocellular carcinoma beyond the Milan criteria. Gut. 2016;65:1035-41.

3. Lai Q, Vitale A, Halazun K, lesari S, Viveiros A, Bhangui P, et al. Identification of an Upper Limit of Tumor Burden for Downstaging in Candidates with Hepatocellular Cancer Waiting for Liver Transplantation: A West-East Collaborative Effort. Cancers (Basel). 2020;12:452.

4. Lee HW, Song GW, Lee SG, Kim JM, Joh JW, Han DH, et al. Patient Selection by Tumor Markers in Liver Transplantation for Advanced Hepatocellular Carcinoma. Liver Transpl. 2018;24:1243-51.

5. Xiao GQ, Yang JY, Yan LN. Combined Hangzhou criteria with neutrophil-lymphocyte ratio is superior to other criteria in selecting liver transplantation candidates with HBV-related hepatocellular carcinoma. Hepatobiliary Pancreat Dis Int. 2015;14:588-95.

6. Kang YK, Choi JY, Paeng JC, Kim YI, Kwon HW, Cheon GJ,et al. Composite criteria using clinical and FDG PET/CT factors for predictingrecurrence of hepatocellular carcinoma after living donor liver transplantation. Eur Radiol. 2019;29:6009-17.

7. DiNorcia J, Florman SS, Haydel B, Tabrizian P, Ruiz RM, Klintmalm GB, et al. Pathologic Response to Pretransplant Locoregional Therapy is Predictive of Patient Outcome After Liver Transplantation for Hepatocellular Carcinoma: Analysis From the US Multicenter HCC Transplant Consortium. Ann Surg. 2020;271:616-24.

8. Agopian VG, Harlander-Locke MP, Ruiz RM, Klintmalm GB, Senguttuvan S, Florman SS, et al. Impact of Pretransplant Bridging Locoregional Therapy for Patients With Hepatocellular Carcinoma Within 
Milan Criteria Undergoing Liver Transplantation: Analysis of 3601 Patients From the US Multicenter HCC Transplant Consortium. Ann Surg. 2017;266:525-35.

9. Bauschke A, Altendorf-Hofmann A, Ardelt M, Kissler H, Tautenhahn HM, Settmacher U. Impact of successful local ablative bridging therapy prior to liver transplantation on long-term survival in patients with hepatocellular carcinoma in cirrhosis. J Cancer Res Clin Oncol. 2020;146:1819-27.

10. Lee KW, Suh SW, Choi Y, Jeong J, Yi NJ, Kim H, et al. Macrovascular invasion is not an absolute contraindication for living donor liver transplantation. Liver Transpl. 2017;23:19-27.

11. Han DH, Joo DJ, Kim MS, Choi GH, Choi JS, Park YN, et al. Living Donor Liver Transplantation for Advanced Hepatocellular Carcinoma with Portal Vein Tumor Thrombosis after Concurrent Chemoradiation Therapy. Yonsei Med J. 2016;57:1276-81.

12. Soin AS, Bhangui P, Kataria T, Baijal SS, Piplani T, Gautam D, et al. Experience With LDLT in Patients with Hepatocellular Carcinoma and Portal Vein Tumor Thrombosis Postdownstaging. Transplantation. 2020 Feb 6. Online ahead of print.

13. Hamaoka M, Kobayashi T, Kuroda S, Iwako H, Okimoto S, Kimura T, et al. Hepatectomy after downstaging of hepatocellular carcinoma with portal vein tumor thrombus using chemoradiotherapy: a retrospective cohort study. Int J Surg. 2017;44:223-8.

14. Lu J, Zhang XP, Zhong BY, Lau WY, Madoff DC, Davidson JC, et al. Management of patients with hepatocellular carcinoma and portal vein tumour thrombosis: comparing east and west. Lancet Gastroenterol Hepatol. 2019;9:721-30.

15. Pommergaard HC, Rostved AA, Adam R, Thygesen LC, Salizzoni M, Gómez Bravo MA, et al. Vascular invasion and survival after liver transplantation for hepatocellular carcinoma: a study from the European liver transplant registry. HPB (Oxford). 2018;20:768-75.

16. Villanueva A. Hepatocellular Carcinoma. N Engl J Med. 2019;380:1450-62.

17. Choi HJ, Kim DG, Na GH, Hong TH, Bae SH, You YK, et al. The clinical outcomes of patients with portal vein tumor thrombi after living donor liver transplantation. Liver Transpl. 2017;23:1023-31.

18. Yang Z, Luo FZ, Wang S, Lerut J, Zhuang L, Li QY, et al. Alpha-fetoprotein and (18)F-FDG standard uptake value predict tumor recurrence after liver transplantation for hepatocellular carcinoma with portal vein tumor thrombosis: Preliminary experience. Hepatobiliary Pancreat Dis Int. 2020 Jun;19(3):229-34.

19. Xiang X, Lau WY, Wu ZY, Zhao C, Ma YL, Xiang BD, et al. Transarterial chemoembolization versus best supportive care for patients with hepatocellular carcinoma with portal vein tumor thrombus: a multicenter study. Eur J Surg Oncol. 2019;45:1460-67.

20. Zhang X, Wang K, Wang M, Yang G, Ye X, Wu M, et al. Transarterial chemoembolization (TACE) combined with sorafenib versus TACE for hepatocellular carcinoma with portal vein tumor thrombus: a systematic review and meta-analysis. Oncotarget. 2017;8:29416-27.

21. Zhao J, Zeng L, Wu Q, Wang L, Lei J, Luo H, et al. Stereotactic Body Radiotherapy Combined with Transcatheter ArterialChemoembolization versus Stereotactic Body Radiotherapy Alone as the First- 
Line Treatment for Unresectable Hepatocellular Carcinoma: A Meta-Analysis and Systematic Review. Chemotherapy. 2010;22:1-11.

22. Que J, Wu HC, $\mathrm{Lin} \mathrm{CH}$, Huang $\mathrm{Cl}, \mathrm{Li} \mathrm{LC}, \mathrm{Ho} \mathrm{CH}$. Comparison of stereotactic body radiation therapy with and without sorafenib as treatment for hepatocellular carcinoma with portal vein tumor thrombosis. Medicine. 2020;99(13):e19660.

23. Chu HH, Kim JH, Shim JH, Yoon SM, Kim PH, Alrashidi I. Chemoembolization Plus Radiotherapy Versus Chemoembolization PlusSorafenib for the Treatment of Hepatocellular Carcinoma Invading the Portal Vein: A Propensity Score Matching Analysis. Cancers (Basel). 2020;12:E1116.

24. Finn RS, Qin S, Ikeda M, Galle PR, Ducreux M, Kim TY, et al. Atezolizumab plus Bevacizumab in Unresectable Hepatocellular Carcinoma. N Engl J Med. 2020;382:1894-905.

\section{Tables}


Table 1

Characteristics of liver transplant recipients with PVTT-HCC

\begin{tabular}{|c|c|c|c|c|}
\hline Variables & $\begin{array}{l}\text { Overall } \\
(n=107)\end{array}$ & $\begin{array}{l}\text { Well response } \\
(n=15)\end{array}$ & $\begin{array}{l}\text { Poor response (n } \\
=33 \text { ) }\end{array}$ & $\begin{array}{l}\text { Non- } \\
\text { downstaged } \\
(n=59)\end{array}$ \\
\hline $\begin{array}{l}\text { Median age, years } \\
\text { (IQR) }\end{array}$ & $49(42-56)$ & $53(48-59)$ & $52(41-60)$ & $48(39-53)$ \\
\hline Sex, male, n (\%) & $97(90.7)$ & $15(100)$ & $29(87.9)$ & $53(89.8)$ \\
\hline $\begin{array}{l}\text { AFP pre-LT, median } \\
\text { (IQR) }\end{array}$ & $\begin{array}{l}602.6(30.8- \\
13719)\end{array}$ & $\begin{array}{l}\text { 118.4 (21.4- } \\
773)\end{array}$ & 1210 (99.7-16859) & $\begin{array}{l}918.4(30.1- \\
17801)\end{array}$ \\
\hline $\begin{array}{l}\text { NLR pre-LT, median } \\
\text { (IQR) }\end{array}$ & $4.9(3.4-8.5)$ & $4.2(2.9-9.8)$ & $3.8(3.1-6.5)$ & $5.6(4.4-10)$ \\
\hline $\begin{array}{l}\text { PLR pre-LT, median } \\
\text { (IQR) }\end{array}$ & $153(94-234)$ & $76(47-190)$ & $150(109-200)$ & $172(109-282)$ \\
\hline $\begin{array}{l}\text { CRP pre-LT, median } \\
\text { (IQR) }\end{array}$ & $18(6.1-38.8)$ & $11(5.0-30.2)$ & $17.9(6.0-54.1)$ & $18.5(9.9-36.8)$ \\
\hline \multicolumn{5}{|c|}{$\begin{array}{l}\text { Maximum tumor size, } \\
\text { n (\%) }\end{array}$} \\
\hline$<8 \mathrm{~cm}$ & $54(50.5)$ & $12(80)$ & $17(51.5)$ & $25(42.4)$ \\
\hline$>8 \mathrm{~cm}$ & $53(49.5)$ & $3(20)$ & $16(48.5)$ & $34(57.6)$ \\
\hline \multicolumn{5}{|c|}{ Total tumor size, n (\%) } \\
\hline$<8 \mathrm{~cm}$ & $27(25.2)$ & $7(46.7)$ & $6(18.2)$ & $14(23.7)$ \\
\hline$>8 \mathrm{~cm}$ & $80(74.8)$ & $8(53.3)$ & $27(81.8)$ & $45(76.3)$ \\
\hline \multicolumn{5}{|l|}{ Tumor number, n (\%) } \\
\hline single & $19(17.8)$ & $4(26.7)$ & $4(12.1)$ & $11(18.6)$ \\
\hline multiple & $88(82.2)$ & $11(73.3)$ & $29(87.9)$ & $48(81.4)$ \\
\hline \multicolumn{5}{|c|}{$\begin{array}{l}\text { Tumor differentiation, } \\
\mathrm{n}(\%)\end{array}$} \\
\hline well-moderate & $60(56.1)$ & $14(93.3)$ & $20(60.6)$ & $26(44.1)$ \\
\hline poor & $47(43.9)$ & $1(6.7)$ & $13(39.4)$ & $33(55.9)$ \\
\hline
\end{tabular}

Patient, tumor, pretransplant treatment and response to downstaging therapy in recipients of liver transplant for HCC with PVTT

HCC, hepatocellular carcinoma; PVTT, portal vein tumor thrombus; IQR, interquartile range; AFP, alphafetoprotein; NLR, neutrophil to lymphocyte ratio; PLR, platelet to lymphocyte ratio; CRP, C-reaction protein; TACE, transarterial chemoembolization. 


\begin{tabular}{|c|c|c|c|c|}
\hline Variables & $\begin{array}{l}\text { Overall } \\
(n=107)\end{array}$ & $\begin{array}{l}\text { Well response } \\
(n=15)\end{array}$ & $\begin{array}{l}\text { Poor response (n } \\
=33)\end{array}$ & $\begin{array}{l}\text { Non- } \\
\text { downstaged } \\
(n=59)\end{array}$ \\
\hline \multicolumn{5}{|l|}{ PVTT grade, n (\%) } \\
\hline Vp2-3 & $62(57.9)$ & $10(66.7)$ & $19(57.6)$ & 33 (55.9) \\
\hline Vp4 & $45(42.1)$ & $5(33.3)$ & $14(42.4)$ & $26(44.1)$ \\
\hline \multicolumn{5}{|c|}{$\begin{array}{l}\text { Modality of treatment, } \\
\mathrm{n}(\%)\end{array}$} \\
\hline TACE alone & $32(66.7)$ & $6(40.0)$ & $25(75.8)$ & $0(0)$ \\
\hline $\begin{array}{l}\text { TACE + systematic } \\
\text { therapies }\end{array}$ & $11(22.9)$ & $7(46.7)$ & $4(12.1)$ & $0(0)$ \\
\hline Other & $5(10.4)$ & $2(13.3)$ & $4(12.1)$ & $0(0)$ \\
\hline \multicolumn{5}{|c|}{$\begin{array}{l}\text { Patient, tumor, pretransplant treatment and response to downstaging therapy in recipients of liver } \\
\text { transplant for HCC with PVTT }\end{array}$} \\
\hline \multicolumn{5}{|c|}{$\begin{array}{l}\text { HCC, hepatocellular carcinoma; PVTT, portal vein tumor thrombus; IQR, interquartile range; AFP, alpha- } \\
\text { fetoprotein; NLR, neutrophil to lymphocyte ratio; PLR, platelet to lymphocyte ratio; CRP, C-reaction } \\
\text { protein; TACE, transarterial chemoembolization. }\end{array}$} \\
\hline
\end{tabular}


Table 2

Univariate and multivariate analysis evaluating predictors of well response to downstaging therapy

\begin{tabular}{|c|c|c|c|c|c|c|}
\hline \multirow[b]{2}{*}{ Variables } & \multicolumn{3}{|c|}{ Univariate Analysis } & \multicolumn{3}{|c|}{ Multivariate Analysis } \\
\hline & OR & $95 \% \mathrm{Cl}$ & $\mathbf{P}$ & OR & $95 \% \mathrm{Cl}$ & $P$ \\
\hline Recipient age $\geq 50$ y & 1.882 & $0.527-6.718$ & 0.330 & & & \\
\hline AFP $\geq 1000 \mathrm{ng} / \mathrm{mL}$, pre-LT & 0.184 & $0.044-0.778$ & 0.021 & & & \\
\hline $\mathrm{NLR} \geq 7$, pre-LT & 1.636 & $0.385-6.951$ & 0.505 & & & \\
\hline PLR $\geq 120$, pre-LT & 0.208 & $0.054-0.799$ & 0.022 & & & \\
\hline CRP $\geq 10 \mathrm{mg} / \mathrm{L}$, pre-LT & 0.653 & $0.189-2.252$ & 0.500 & & & \\
\hline Maximum tumor size $>8 \mathrm{~cm}$ & 0.266 & $0.063-1.118$ & 0.071 & & & \\
\hline Total tumor size $>8 \mathrm{~cm}$ & 0.254 & $0.066-0.976$ & 0.046 & & & \\
\hline Tumor number, multiple & 0.379 & $0.081-1.787$ & 0.220 & & & \\
\hline Tumor differentiation, poor & 0.110 & $0.013-0.939$ & 0.044 & 0.060 & $0.005-0.693$ & 0.024 \\
\hline PVTT grade (Vp4 vs Vp2-3) & 0.679 & $0.189-2.432$ & 0.552 & & & \\
\hline Combined therapies $^{b}$ & 6.400 & $1.593-25.717$ & 0.009 & 10.884 & $1.909-62.047$ & 0.007 \\
\hline \multicolumn{7}{|c|}{$\begin{array}{l}\text { Poorly differentiated HCC was independent risk factor associated with well response, and multiple } \\
\text { combined downstaging therapies was independent favorable factor associated with well response }\end{array}$} \\
\hline \multicolumn{7}{|c|}{$\begin{array}{l}\text { AFP, alpha-fetoprotein; NLR, neutrophil to lymphocyte ratio; PLR, platelet to lymphocyte ratio; CRP, C- } \\
\text { reaction protein; PVTT, portal vein tumor thrombus; OR, odds ratio; Cl, confidence interval. }\end{array}$} \\
\hline
\end{tabular}


Table 3

Univariate analysis of tumor recurrence and overall survival

\section{Tumor Recurrence}

\begin{tabular}{|c|c|c|c|c|c|c|}
\hline Variables & $\mathrm{HR}$ & $95 \% \mathrm{Cl}$ & $\mathbf{P}$ & $\mathrm{HR}$ & $95 \% \mathrm{Cl}$ & $\mathbf{P}$ \\
\hline Recipient age $\geq 50$ y & 0.803 & $0.509-1.268$ & 0.347 & 0.774 & $0.435-1.377$ & 0.384 \\
\hline Recipient gender, male & 0.687 & $0.329-1.432$ & 0.687 & 0.597 & $0.252-1.411$ & 0.240 \\
\hline AFP $\geq 1000 \mathrm{ng} / \mathrm{mL}$, pre-LT & 2.679 & $1.682-4.266$ & $\hat{0} .001$ & 3.325 & $1.795-6.160$ & $<0.001$ \\
\hline $\mathrm{NLR} \geq 7$, pre-LT & 1.909 & $1.182-3.082$ & 0.008 & 2.511 & $1.409-4.477$ & 0.002 \\
\hline PLR $\geq 120$, pre-LT & 2.285 & $1.366-3.823$ & 0.002 & 2.246 & $1.142-4.415$ & 0.019 \\
\hline $\mathrm{CRP} \geq 10 \mathrm{mg} / \mathrm{L}$, pre-LT & 2.109 & $1.251-3.555$ & 0.005 & 4.451 & $1.884-10.515$ & 0.001 \\
\hline $\begin{array}{l}\text { Maximum tumor size > } \\
8 \mathrm{~cm}\end{array}$ & 2.621 & $1.632-4.208$ & $<.001$ & 2.133 & $1.175-3.871$ & 0.013 \\
\hline Total tumor size $>8 \mathrm{~cm}$ & 2.560 & $1.376-4.764$ & 0.003 & 3.172 & $1.254-8.021$ & 0.015 \\
\hline Tumor number, multiple & 1.266 & $0.682-2.349$ & 0.455 & 1.483 & $0.629-3.493$ & 0.368 \\
\hline Tumor differentiation, poor & 1.770 & $1.123-2.790$ & 0.014 & 2.643 & $1.464-4.771$ & 0.001 \\
\hline PVTT grade (Vp4 vs Vp2-3) & 1.852 & $1.173-2.925$ & 0.008 & 2.804 & $1.553-5.064$ & 0.001 \\
\hline Pretransplant treatment & 0.641 & $0.399-1.029$ & 0.065 & 0.847 & $0.473-1.517$ & 0.577 \\
\hline Tumor necrosis > 50\% & 0.234 & $0.085-0.642$ & 0.005 & 0.110 & $0.015-0.797$ & 0.029 \\
\hline Combined therapies ${ }^{b}$ & 0.267 & $0.080-0.888$ & 0.031 & 0.134 & $0.018-1.003$ & 0.050 \\
\hline
\end{tabular}

Risk factors on posttransplant HCC recurrence and overall survival in patients with PVTT ${ }^{\text {a }}$. Univariate Cox regression analyses were carried out to determine predictors of tumor recurrence and overall survival

$\mathrm{HR}$, risk ratio; $95 \% \mathrm{Cl}, 95 \%$ confidence interval; $\mathrm{HCC}$, hepatocellular carcinoma; AFP, alpha-fetoprotein; NLR, neutrophil to lymphocyte ratio; PLR, platelet to lymphocyte ratio; CRP, C-reaction protein; PVTT, portal vein tumor thrombus; $\mathrm{HR}$, hazard ratio; $\mathrm{Cl}$, confidence interval.

${ }^{a}$ Cox proportional hazards regression

b Transarterial chemoembolization, tyrosine kinase inhibitors and PD-1 antibody 
Table 4

Multivariable analysis of tumor recurrence and overall survival

Tumor Recurrence

\begin{tabular}{lllllll} 
Variables & HR & $95 \% \mathrm{Cl}$ & $\mathrm{P}$ & $\mathrm{HR}$ & $95 \% \mathrm{Cl}$ & $\mathrm{P}$ \\
\hline AFP $\geq 1000 \mathrm{ng} / \mathrm{mL}$, pre-LT & 3.032 & $1.303-7.057$ & $\mathbf{0 . 0 1 0}$ & 3.287 & $1.154-9.368$ & $\mathbf{0 . 0 2 6}$ \\
\hline Tumor necrosis $>50 \%$ & 0.311 & $0.102-0.954$ & $\mathbf{0 . 0 4 1}$ & 0.116 & $0.015-0.889$ & $\mathbf{0 . 0 3 8}$
\end{tabular}

Multivariate analysis evaluating risk factors on posttransplant HCC recurrence and overall survival in the subset of patients with PVTT ${ }^{a}$. Variables displaying a $p$ value $<0.05$ were included in the multivariable Cox regression model

AFP, alpha-fetoprotein; HCC, hepatocellular carcinoma; PVTT, portal vein tumor thrombus; HR, hazard ratio; $\mathrm{Cl}$, confidence interval.

a Cox proportional hazards regression

\section{Figures}

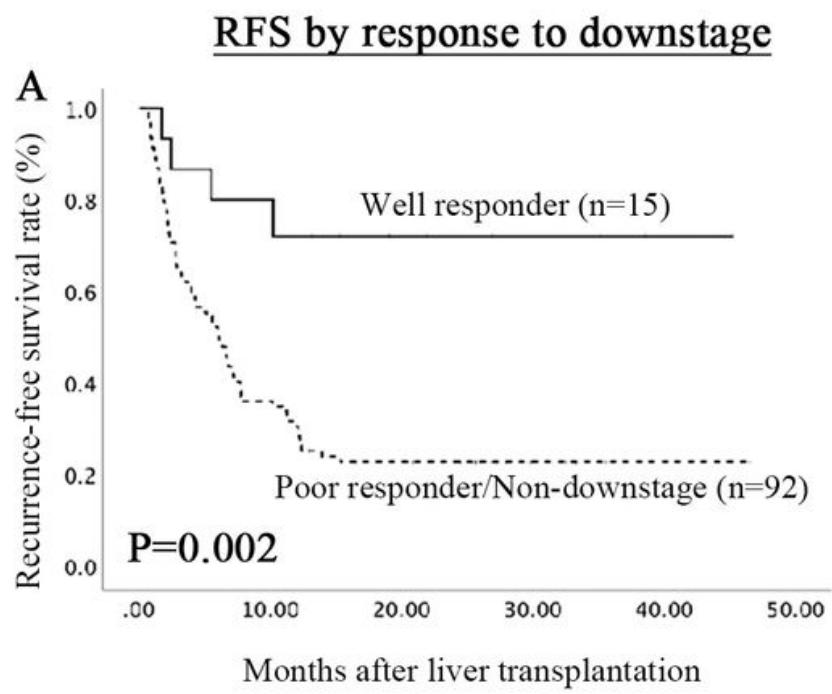

\begin{tabular}{lccc}
\hline Recurrence-free survival rate & 1 year & 2 year & 3 year \\
\hline Well responder & $72 \%$ & $72 \%$ & $72 \%$ \\
Poor responder & $30.4 \%$ & $22.6 \%$ & $22.6 \%$ \\
Non-downstage & & & \\
\hline
\end{tabular}

\section{OS by response to downstage}

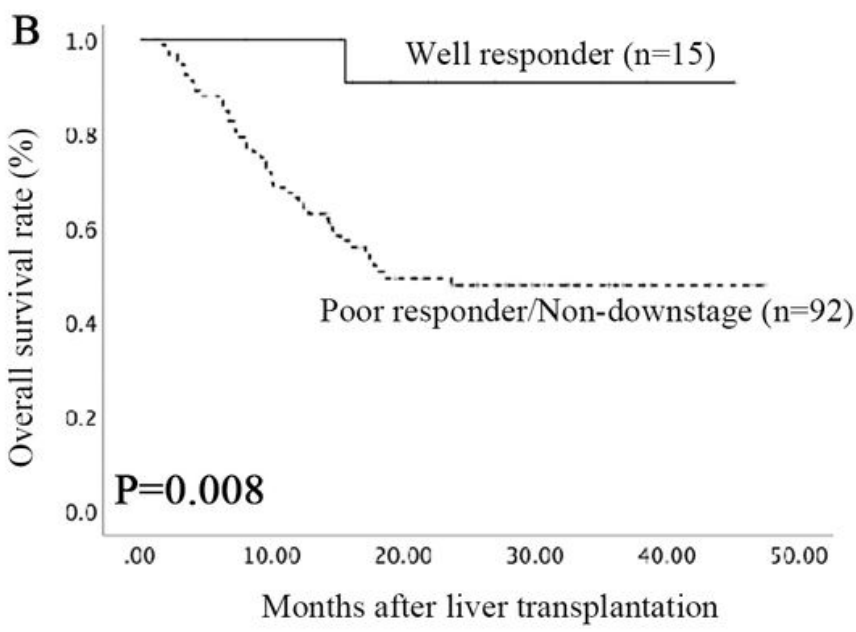

\begin{tabular}{llll}
\hline Overall survival rate & 1 year & 2 year & 3 year \\
\hline Well responder & $100 \%$ & $90.9 \%$ & $90.9 \%$ \\
Poor responder & $66.3 \%$ & $47.7 \%$ & $47.7 \%$ \\
Non-downstage & & & \\
\hline
\end{tabular}

\section{Figure 1}

Outcome of HCC patients with PVTT who underwent LT. Kaplan-Meier RFS (A) and overall survival (B) after LT for HCC with PVTT stratified by radiographic response after pretransplant downstaging therapy. 
HCC, hepatocellular carcinoma; PVTT, portal vein tumor thrombus; LT, liver transplantation; RFS, recurrence-free survival; OS, overall survival. 